\title{
Peningkatan Keterampilan Pengurusan Jenazah di MTs Ulumul Quran Medan
}

\author{
Sahmiar Pulungan \\ UIN Sumatera Utara/ Fakultas Syari'ah dan Hukum \\ sahmiarpulungan@gmail.com \\ Sahliah \\ UIN Sumatera Utara/ Fakultas Syari'ah dan Hukum \\ sahliahsb13@gmail.com \\ Sarudin \\ Universitas Harapan Medan/ Teknik Informatika \\ udinalga@gmail.com \\ Dharmawati \\ Universitas Harapan Medan/ Teknik Informatika \\ dharmawati66@yahoo.com
}

Naskah diterima: 5 Desember 2019| Naskah disetujui: 8 Februari 2020

\begin{abstract}
Every living creature in this world will surely death, it means that death is a provision for every creature that has been created, nothing is eternal in this world except Allah SWT. The purpose of this service is to give training in improving students' skill about fardhu kifayah in MTs Ulumul Qur'an Medan so that the students can have understanding and knowledge to organize the corpse handling. This training program will produce understanding and implementing fardu kifayah for students in MTs Ulumul Qur'an. The stage in this activity started from the students' need to practice in organizing the corpse. The method used in this activity was speech and practice. After giving theoretical knowledge through speech and discussion metod, the students will be given training and practiceing to organize the cropse from beginning to bath, warp corpse, have a corpse prayer and buried. The result of this service was the students have the ability not only theoritically but also practically in in organizing the corpse.
\end{abstract}

Keywords: Fardu Kifayah, Organizing the Corpse

\begin{abstract}
Abstrak
Setiap makhluk yang hidup di dunia ini pasti akan mengalami kematian, itu artinya bahwa kematian adalah suatu ketetapan bagi setiap makhluk yang telah diciptakan, tak ada yang kekal dan tak ada yang abadi kecuali Allah SWT. Tujuan dilaksanakannya pengabdian ini adalah untuk memberikan pelatihan peningkatan keterampilan siswa dalam pengurusan jenazah di MTs Ulumul Quran Medan sehinggan para siswa memiliki pemahaman dan wawasan terhadap pengurusan jenazah. Pelatihan ini akan menghasilkan paham dalam melaksanakan fardhu kifayah bagi siswa-siswa di MTs
\end{abstract}


Ulumul Qur'an. Kegiatan pengabdian ini dimulai dari kebutuhan siswa untuk melakuka praktek pengurusan jenazah. Metode yang digunakan dalah metode ceramah dan praktek. Setelah diberikan pengetahuan teoritis melalui metode ceramah dan diskusi, para siswa diberikan pelatihan dan praktek dalam pengurusan jenazah dari mulai memandikan, mengkhafani, mensholatkan dan menguburkan jenazah. Hasil dari kegiatan ini adalah para siswa memiliki peningkatan kemampuan tidak saja secara teoritis tapi juga praktis dalam pengurusan jenazah.

Kata kunci: Fardu Kifayah, Pengurusan Jenazah

\section{Pendahuluan}

Perkembangan zaman dan teknologi yang begitu pesat ditambah dengan indahnya gemerlap dunia membuat banyak manusia tertipu oleh daya tarik dunia ini yang sesungguhnya dunia ini hanyalah sebagai tempat persinggahan kita yang sementara sedangkan tempat kita yang abadi dan kekal adalah di akhirat kelak. Banyak orang yang tidak percaya akan adanya akhirat sehingga menyepelekan masalah yang satu ini, ada pula yang dikarenakan perkembangan zaman hingga banyak orang melupakan akan akhirat sehingga kondisi seperti ini akan terjadi terus menerus dan turun menurun yang mengakibatkan rusaknya akidah-akidah Islam yang tidak lain yang merusaknya adalah orang Islam itu sendiri.

Syariat Islam mengajarkan bahwa setiap manusia pasti akan mengalami kematian yang tidak pernah diketahui kapan waktunya. Sebagai makhluk sebaik-baik ciptaan Allah SWT dan ditempatkan pada derajat yang tinggi, maka Islam sangat menghormati orang muslim yang telah meninggal dunia. Oleh sebab itu, menjelang menghadapi keharibaan Allah SWT orang yang telah meninggal dunia mendapatkan perhatian khusus dari muslim lainnya yang masih hidup.

Apabila seseorang telah meninggal dunia, hendaklah seorang dari mahramnya yang paling dekat dan sama jenis kelaminnya melakukan kewajiban yang mesti dilakukan terhadap jenazah, yaitu memandikan, mengkafani, menyembahyangkan dan menguburkannya. Menyelenggarakan jenazah, yaitu sejak dari menyiapkannya, memandikannya, mengkafaninya, menshalatkannya, membawanya ke kubur sampai kepada menguburkannya adalah perintah agama yang ditujukan kepada kaum muslimin sebagai kelompok masyarakat. Apabila perintah itu telah dikerjakan oleh sebahagian mereka sebagaimana mestinya, maka kewajiban melaksanakan perintah itu berarti sudah terbayar. Kewajiban yang demikian sifatnya dalam istilah agama dinamakan fardhu kifayah, hal ini berdasarkan hadits Nabi SAW yang diriwayatkan oleh Aisyah ra yaitu:

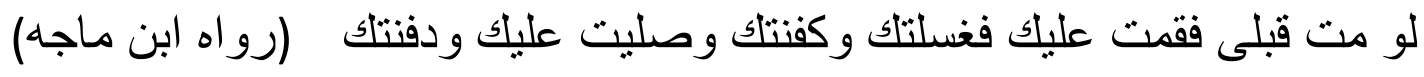

"Apabila engkau meninggal sebelumku, niscaya aku akan memandikanmu dan mengkafanimu, menyalatimu serta menguburkanmu”.(H.R. Ibnu Majah)

Dalam hadis lain dari Abdullah bin Abbas radhiyallahu'anhu, beliau menjelaskan: 


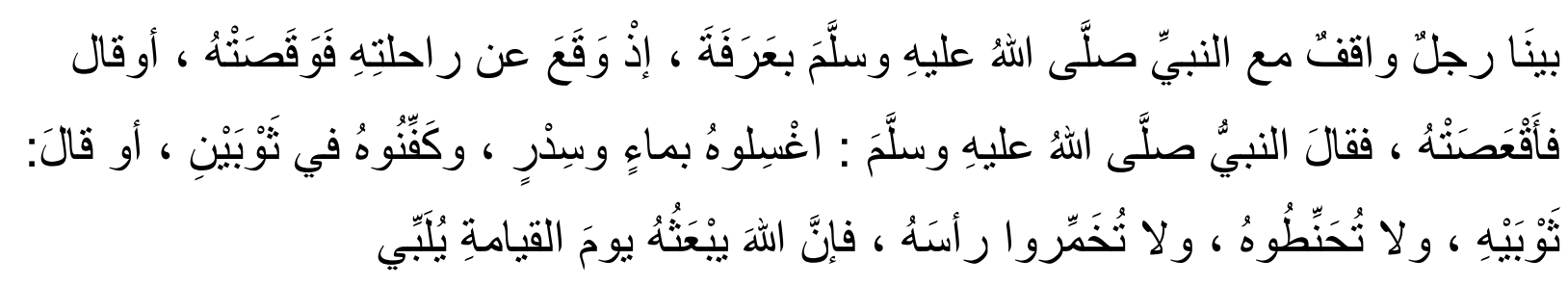

Artinya: " Ada seorang lelaki yang sedang wukuf di Arafah bersama Nabi Shallallahu'alaihi Wasallam. Tiba-tiba ia terjatuh dari hewan tunggangannya lalu meninggal. Maka Nabi Shallallahu'alaihi Wasallam bersabda: mandikanlah ia dengan air dan daun bidara Dan kafanilah dia dengan dua lapis kain, jangan beri minyak wangi dan jangan tutup kepalanya. Karena Allah akan membangkitkannya di hari Kiamat dalam keadaan bertalbiyah".

(HR. Bukhari no. 1849, Muslim no. 1206).

Hadis di atas menjelaskan tentang pengurusan jenazah bagi orang yang hidup yaitu fardu kifayah. Artinya sebahagian melaksanakannya maka lepaslah dosa orang yang tidak ikut melaksanakannya.

Untuk membina generasi ini, dapat dimulai dari pembelajaran PAI di sekolah, khususnya pada siswa-siswa yang duduk di bangku tingkat pertama. Pelatihan pengurusan jenazah harus diberikan kepada siswa-siawa agar mereka mengerti dan memahami tentang pengurusan jenazah sejak dini. Namun kenyataannya masih banyak sekolah khususnya sekolah tingkat pertama yang memberikan pembelajaran tentang pengurusan jenazah sekedar saja. Sehingga wawasan para siswa terhadap pengurusan jenazah sangat rendah bahkan tidak tahu. Sehingga diperlukan pelatihan tentang pengurusan jenazah di sekolah tingkat pertama.

Sekolah MTS Ulumul Quran teletak di tengah kota tepatnya di J1, Teladan no, 43, Kelurahan Teladan Barat, Kecamatan Medan Kota, Provinsi Sumatera Utara. Sekolah ini merupakan sekolah yang menekankan pada pendidikan agama Islam. Pembelajaran yang digunakan di sekolah ini umumnya menggunakan metode ceramah. Pengurusan jenazah merupakan salah satu topik pelajaran PAI yang telah mereka pelajari. Namun dalam pembelajaran pengurusan jenazah, guru tidak memberikan contoh atau praktek tentang bagaimana cara pengurusan jenazah yang benar. Sehingga pemahaman dan wawasan para siswa khususnya keles IX tentang pengurusan jenazah sangat rendah.

Berdasarkan pengamatan tersebut perlu dilakukan pelatihan pengurusan jenazah disekolah MTs Umulul Quran agar para siswa memiliki pengetahuan yang baik tentang tata cara pengurusan jenazah. Melalui kegiatan pengabdian kepada masyarakat pelatihan pengurusan jenazah di MTs Ulumul Quran Medan diharapkan dapat mencapai tujuan yang telah dirumuskan yaitu agar siswasiswa mengetahui dan mengerti tata cara dalam penyelenggaraan jenazah, diharapkan para siswa mampu menjadikan pelatihan ini sebagai pedoman dalam kehidupan sehari-hari yang mempermudah sanak keluarga apabila keluarga tersebut terdapat keluarganya yang baru saja meninggal yang mampu diurus oleh anggota keluarga tersebut.

\section{Tema Kajian}

Kata jenazah, bila ditinjau dari segi bahasa (etimologis), berasal dari bahasa Arab dan menjadi turunan dari isim masdar (adjective) yang diambi dari fi'il madi janaza-yajnizu- 
janazatan wa jinazatan. Bila huruf jim dari kata tersebut dibaca fathah (janazatan), kata ini berarti orang yang telah meninggal dunia. Dalam kamus al-Munawwir, kata jenazah diartikan sebagai "seseorang yang telah meninggal dunia dan diletakkan dalam usungan" (Munawwir, 1997).

Menurut istilah, kata jenazah ialah seseorang yang meninggal dunia dan berpisahnya roh dengan jasadnya. Lebih jauh, kata Jenazah memiliki makna "seseorang yang telah meninggal dunia yang sudah terputus masa kehidupannya dengan alam dunia ini" (Hassan, 2000). Jenazah adalah orang yang telah keluar ruh (nyawa) dari jasadnya, atau juga disebut mayat. Umat Islam yang masih hidup berkewajiban untuk mengurusinya. Artinya melakukan hal-hal yang berkenaan dengan mayat sesuai dengan syara'. Hukum penyelenggaraan jenazah menurut kesepakatan ulama adalah fardhu kifayah.

Disunnahkan untuk segera memandikan mayat dan mempersiapkan penguburannya apabila dia telah benar-benar mati, seperti mati dikarenakan suatu sebab atau muncul tanda-tanda kematiannya seperti kedua telapak kakinya menjadi lembek dan tidak tegak, atau hidungnya miring atau pelipisnya berlubang atau meleleh kulit wajahnya, atau copot kedua mata kakinya dari betisnya atau menyusut buah testisnya, apabila ragu karena tidak ada sebab yang membuatnya mati, atau kemungkinan dia hanya diam atau muncul tanda-tanda yang menakutkan atau lainnya, hendaknya ditunggu hingga benar-benar bahwa dia mati, misalnya dengan baunya yang berubah atau lainnya (Ad-Dimasyqi, Yahya, 2010).

Pengurusan jenazah merupakan bagian dari etika Islam yang diajarkan oleh Nabi Muhammad SAW kepada umatnya. Hukum dalam pengurusan jenazah merupakan fardhu kifayah, artinya apabila telah dilaksanakan oleh sebagian orang, maka kewajiban tersebut dianggap telah mencukupi. Pada hakekatnya setiap yang bernyawa itu akan merasakan mati, karena kehidupan dunia itu hanyalah sementara, sebagaimana didalam Q.S Al-Imran ayat: 185.

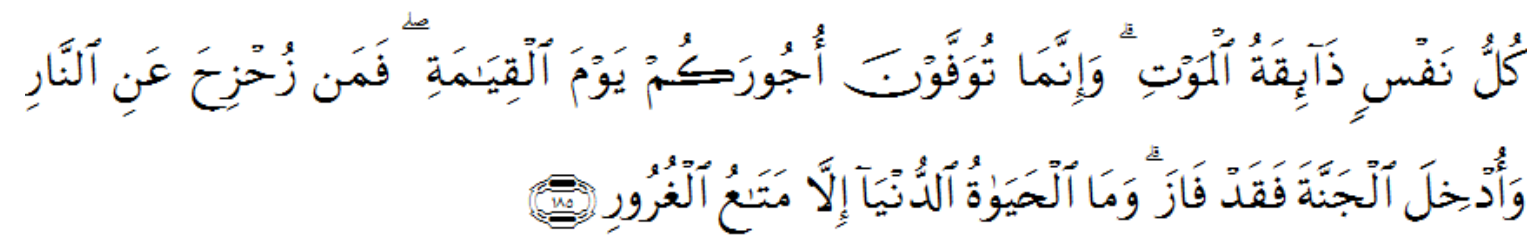

"Tiap-tiap yang berjiwa akan merasakan mati. Dan sesungguhnya pada hari kiamat sajalah disempurnakan pahalamu. Barangsiapa dijauhkan dari neraka dan dimasukkan ke dalam surga, maka sungguh ia telah beruntung. Kehidupan dunia itu tidak lain hanyalah kesenangan yang memperdayakan".

Ayat ini menganjurkan kepada kita semua agar selalu mengingat kematian yang suatu saat pasti akan tiba dan mempersiapkan diri dengan sebaiknya untuk menyambut kematian tersebut.

Dalam Islam ada empat kewajiban orang hidup terhadap jenazah yaitu memandikan, mengafani, menshalatkan dan menguburkannya.

\section{Memandikan Jenazah}

Hukum memandikan jenazah orang yang beragama Islam adalah wajib dan pelaksanaannya adalah fardhu kifayah, dalam artian jika sebagian orang telah melakukannya maka kewajiban tersebut gugur dari orang Islam yang lain. Adapun syarat-syarat orang yang diperbolehkan untuk 
memandikan jenazah sebagaimana dikutip Kamil (2008) adalah orang-orang yang telah memenuhi syarat-syarat sebagai berikut:

a. Islam, berakal dan baligh

b. Niat memandikan jenazah

c. Bisa dipercaya (merahasiakan aib dan cacat tubuh jenazah).

d. Mengetahui tata cara memandikan jenazah.

Orang yang utama untuk memandikan jenazah orang tertentu berbeda antara jenazah laki-laki dan perempuan.

a) Bagi jenazah laki-laki, orang yang utama untuk memandikan jenazah laki-laki urutannya adalah sebagai berikut :

1. Orang yang mendapat wasiat untuk memandikan.

2. Bapak, kakek, kerabat dekat dan mahrim laki-laki dan istri dari yang meninggal.

b) Bagi jenazah wanita, orang yang lebih utama untuk memandikan jenazah perempuan urutannya adalah:

1. Ibu, nenek, kerabat dekat dari pihak perempuan.

2. Suami dari jenazah.

\section{Mengafani Jenazah}

Setelah memandikan jenazah maka yang harus dilakukan adalah mengkafaninya. Kafan yang digunakan untuk membungkus jenazah hendaklah mencukupi untuk menutupi seluruh tubuhnya. Hukum mengkafani jenazah atau mayat juga fardlu kifayah. Mengkafani mayat berarti membungkus mayat dengan selembar kain atau lebih yang biasanya berwarna putih, setelah mayat selesai dimandikan dan sebelum dishalatkan serta dikubur.

\section{Menshalatkan Jenazah}

Menshalatkan jenazah orang islam sesudah dikafani merupakan fardu kifayah. Shalat jenazah adalah shalat yang dilakukan untuk mendo'akan jenazah (mayat) seorang Muslim. Dalam berbagai haditsnya Nabi Muhammad Saw. memerintahkan kepada kita agar melakukan shalat jenazah ini jika di antara saudara kita yang muslim meninggal dunia. Dari hadits-hadits itu jelaslah bahwa shalat jenazah itu sangat dianjurkan, meskipun anjuran untuk shalat jenazah ini tidak sampai wajib atau fardlu 'ain.

\section{Mengubur Jenazah}

Mengubur jenazah merupakan prosesi terakhir dari perawatan jenazah. Hukumnya juga fardlu kifayah seperti tiga perawatan sebelumnya. Waktunya boleh siang dan boleh malam, asal tidak pas waktu matahari terbit, matahari terbenam, atau matahari tepat di atas kita (tengah hari).

Pengurusan jenazah merupakan frdu kufayah bagi kita yang ditinggalkan, dan merupakan kewajiban untuk mengurusnya. Namun ditemukan di masyarakat, banyak yang belum mengetahui bagaimana cara pengurusan jenazah dari mulai jenazah dimandikan, dikafani dan disholatkan dan juga dikuburkan. Pada pendidikan formal seperti di SMP, pengurusan jenazah merupakan materi yang terdapat didalam kurikulum mata pelajaran PAI. Namun dalam teorinya, guru selalu mengajarkan pelajaran pengurusan jenazah sebatas teori saja. Tentunya pengurusan jenazah 
membutuhkan praktek agar menjadi pengetahuan dan pemahaman bagi siswa di masyarakat tentang pengurusan jenazah ini.

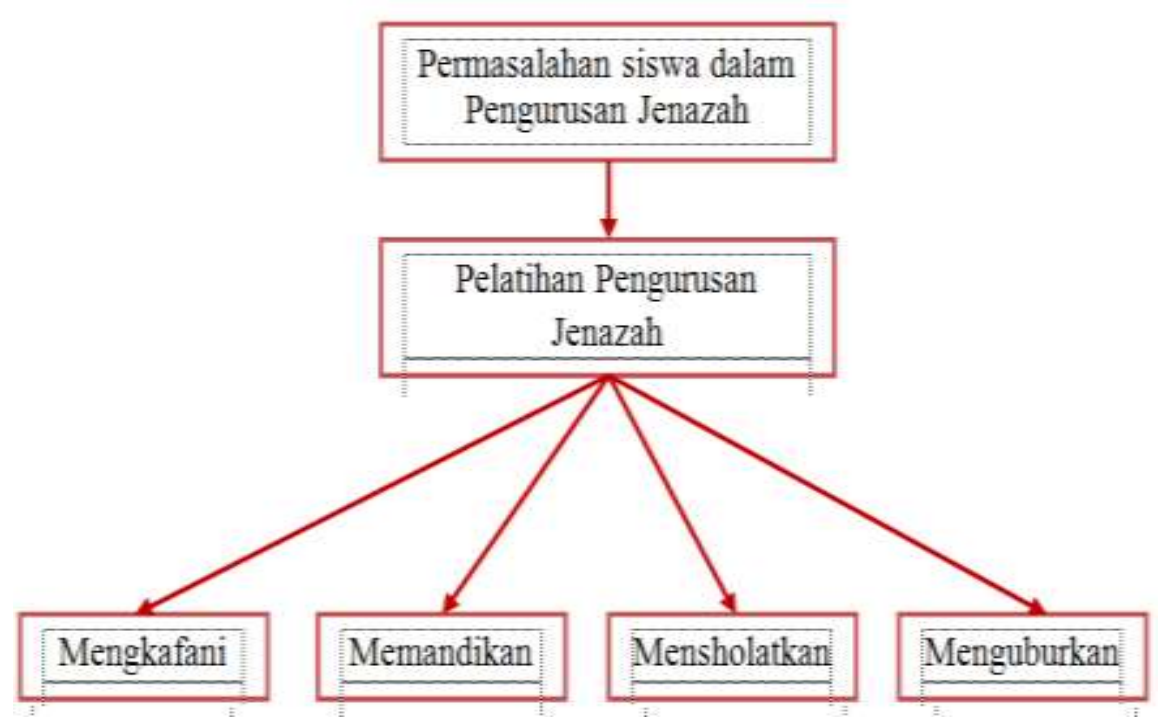

Gambar 1 Kerangka Berpikir Pelatihan Pengurusan Jenazah

\section{Hasil dan Pembahasan}

Setelah manusia meninggal, ada beberapa hak yang masih didapatkan oleh mayat tersebut yang harus dipenuhi oleh manusia yang masih hidup. Menurut ijma' ulama hukumnya fardu kifayah yakni jika sebagian dari mereka telah melakukannya maka gugurlah kewajiban itu atas yang lain, tetapi jika semua meninggalkannya maka semuanya bertanggung jawab dan akan dihisab. Menyelenggarakan empat perkara dalam urusan mayat muslim, di antaranya adalah memandikan, mengkafani, menshalatkan, menguburkan.

\section{Memandikan Jenazah}

Jenazah yang wajib dimandikan ialah mayat muslim yang tidak terbunuh dalam peperangan melawan kaum kafir. Peralatan-peralatan yang perlu dipersiapkan untuk memandikan jenazah, yaitu antara lain sebagai berikut:

1. Tempat tidur atau meja dengan ukuran kira-kira tinggi $90 \mathrm{~cm}$, lebar $90 \mathrm{~cm}$, dan panjang 200 $\mathrm{cm}$, untuk meletakkan mayit.

2. Air suci secukupnya di ember atau tempat lainnya (6-8 ember).

3. Gayung secukupnya (4-6 buah).

4. Kendi atau ceret yang diisi air untuk mewudukan mayit.

5. Tabir atau kain untuk menutup tempat memandikan mayit.

6. Gunting untuk melepaskan baju atau pakaian yang sulit dilepas.

7. Sarung tangan untuk dipakai waktu memandikan agar tangan tetap bersih, terutama bila mayitnya berpenyakit menular.

8. Sabun mandi secukupnya, baik padat maupun cair.

9. Sampo untuk membersihkan rambut.

10. Kapur barus yang sudah dihaluskan untuk dicampur dalam air.

11. Kalau ada daun bidara juga bagus untuk dicampur dengan air. 
12. Tusuk gigi atau tangkai padi untuk membersihkan kuku mayit dengan pelan.

13. Kapas untuk membersihkan bagian tubuh mayit yang halus, seperti mata, hidung, telinga, dan bibir.

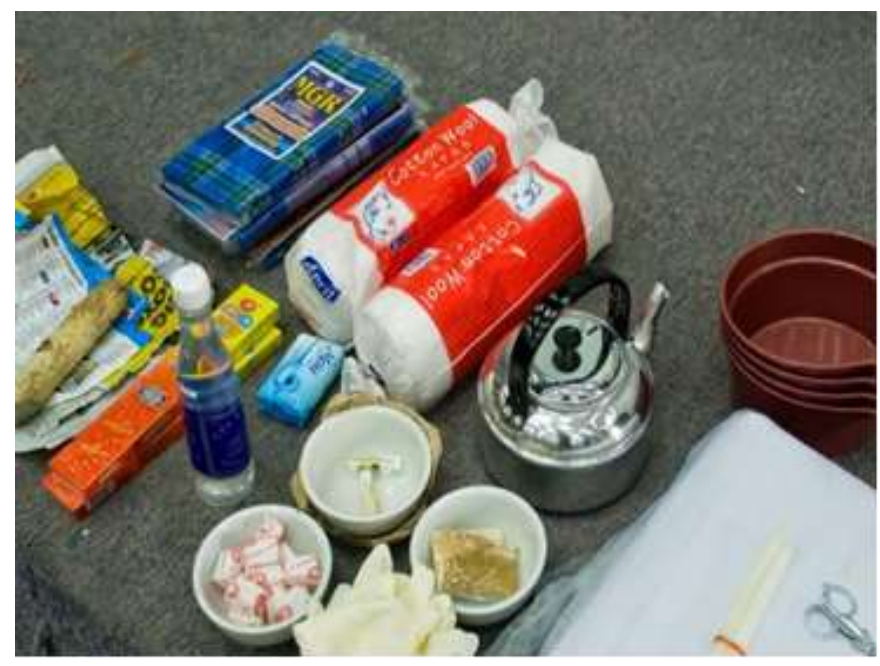

Gambar 2 Peralatan Memandikan Jenazah

Berikut ini adalah tata cara memandikan jenazah menurut syariat Islam:

1. Dilaksanakan di tempat tertutup agar yang melihat hanya orang-orang yang memandikan dan yang mengurusnya saja.

2. Mayat hendaknya diletakkan di tempat jenazah yang tinggi seperti dipan.

3. Jenazah dipakaikan kain basahan seperti sarung agar auratnya tidak terbuka.

4. Jenazah didudukkan atau disandarkan pada sesuatu, lantas disapu perutnya sambil ditekan pelanpelan agar semua kotorannya keluar, kemudian dibersihkan dengan tangan kirinya, dianjurkan mengenakan sarung tangan. Dalam hal ini boleh memakai wangi-wangian agar tidak terganggu bau kotoran si mayat.

5. Setelah itu, hendaklah mengganti sarung tangan untuk membersihkan mulut dan gigi jenazah tersebut.

6. Membersihkan semua kotoran dan najisnya.

7. Mewudhukan jenazah, setelah itu membasuh seluruh badannya.

8. Disunahkan membasuh jenazah sebanyak tiga sampai lima kali.

9. Air untuk memandikan jenazah sebaiknya dingin. Kecuali udara sangat dingin atau terdapat kotoran yang sulit dihilangkan, boleh menggunakan air hangat.

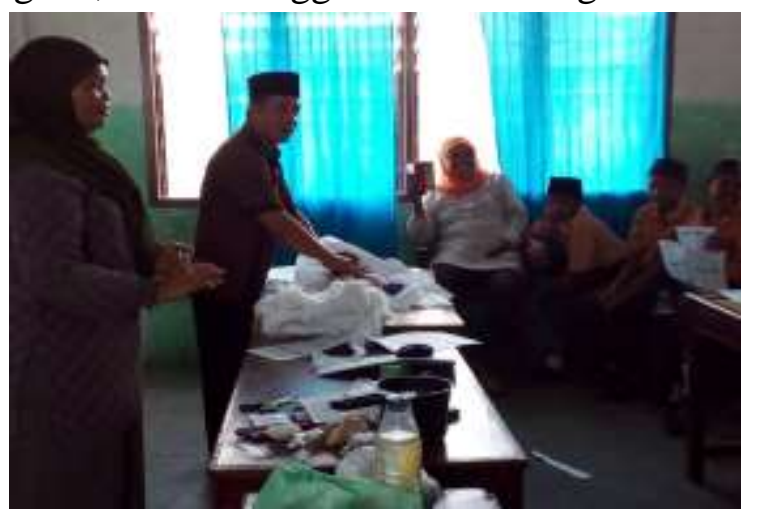

Gambar 3 Memandikan Jenazah 


\section{Mengkafani Jenazah}

Kain kafan hendaknya kain yang bersih, berwarna putih dan sederhana yakni tidak mahal harganya dan tidak pula terlalu murah. Setelah usai memandikan jenazah, maka diwajibkan mengkafaninya. Kafan yang digunakan utuk membungkus jenazah hendaklah mencukupi untuk menutup seluruh tubuhnya. Mengkafani jenazah dilakukan dengan cara: dianjurkan mengkafani dengan 3 helai kain kafan yang berwarna putih bagi jenazah laki-laki, dan 5 helai kain kafan untuk jenazah perempuan. Kain kafan tersebut dibubuhi wewangian kemudian membalut jenazah dengan kain kafan tersebut.

Pada lapis yang pertama dibubuhi wewangian khusus, kemudian letakkan jenazah diatas kafan tersebut dalam posisi terlentang. Lalu letakkan kapas yang telah dibubuhi wewangian pada selakangan jenazah. Hendaklah menyediakan kain yang telah dibubuhi kapas untuk menutupi aurat jenazah dengan melilitkannya (seperti popok) kemudian hendaklah membubuhi wewangian pada lekuk wajah jenazah. Kemudian lembaran pertama dilipat dari sebelah kanan terlebih dahulu, menyusul lembaran kedua dan ketiga seperti halnya lembaran yang pertama. Kemudian menambatkan tali-tali pengikatnya yang berjumlah tujuh utas tali. Lalu gulung lebihan kain kafan pada ujung kepala dan kakinya agar tidak lepas ikatannya, kemudian lipat kea rah kaki dan arah kepala. Jenazah wanita dikafani dengan lima helai kain yaitu kain sarung untuk menutupi bagian bawahnya, kerudung untuk menutupi bagian kepalanya, baju kurung (yang terbuka sisi kanan dan kirinya) serta dua helai kain yang digunakan untuk menutupi sekujur tubuhnya.

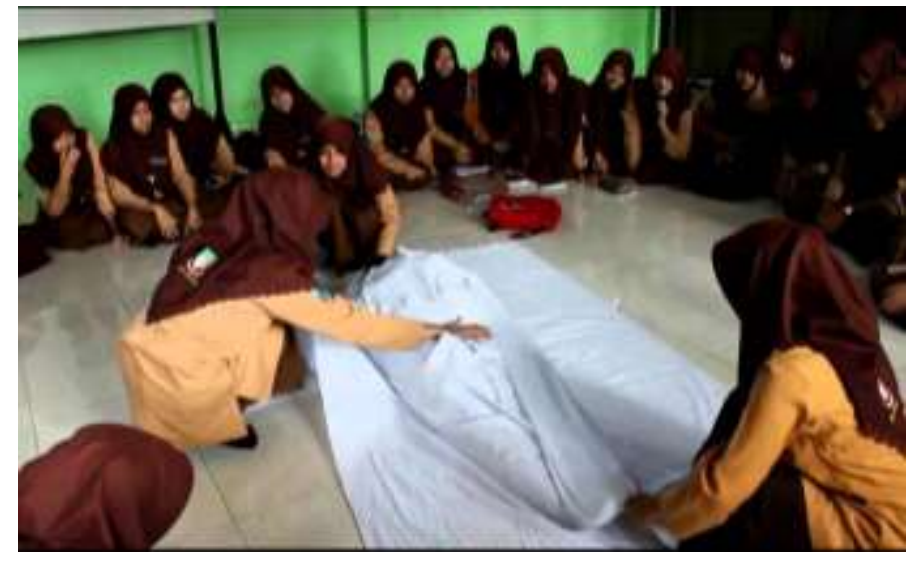

Gambar 4 Mengkafani Jenazah

\section{Menshalatkan Jenazah}

Menurut ulama Hanafiyah dan as-Salafiyah boleh dikerjakan pada sembarang waktu, walaupun di waktu yang dimakruhkan. Sedangkan menurut Ahmad dan Ibnu Mubarak dimakruhkan pada saat terbit dan tenggelamnya matahari. Sholat jenazah ialah sholat yang dikerjakan sebanyak 4 takbir dalam rangka mendo'akan orang muslim yang meninggal (Karim, 2004). Apabila jenazahnya laki-laki imam hendaklah berdiri lurus di depan kepalannya, dan apabila jenazahnya perempuan hendaklah imam menghadap setengah perut atau punggungnya. Rukun sholat jenazah adalah sebagai berikut:
a. Niat
b. Berdiri jika mampu
c. Takbir empat kali 

d. Membaca surat Al-Fatihah
e. Membaca sholawat Nabi saw
f. Mendoakan mayat setelah takbir ketiga dan keempat

Shalat jenazah tidak disertai dengan rukuk dan sujud tidak dengan adzan dan iqmat. Setelah berdiri sebagaimana mestinya, maka:

1. Berdiri menghadap kiblat. Jika jumlah yang melakukan shalat itu banyak, jadikan 3 saf dan dapat lebih.

2. Berniat dengan lafal niatnya:

Untuk jenazah laki-laki : "Ushalli 'alaa haadzal mayyiti arba 'a takbiiraatin fardhu kifaayati ma'muuman/imaaman lillahi ta'aalaa, Allahu akbar " Untuk jenazah perempuan : " Ushalli 'alaa haadzihil mayyitati arba 'a takbiiraatiin fardhu kifaayati ma'muuman/imaaman lillahi ta 'aalaa, Allaahu akbar"

3. Takbiratul Ihram (takbir yang pertama) kemudian membaca surat_Al Fatihah.

4. Takbir kedua kemudian membaca shalawat atas Rasulullah SAW minimal :

"Allahumma Shalli 'alaa Muhammadin" artinya : "Yaa Allah berilah salawat atas nabi Muhammad".

5. Takbir ketiga kemudian membaca do'a untuk jenazah minimal:

"Allahhummaghfir lahu warhamhu wa'aafihi wa'fu anhu" yang artinya : "Yaa Allah ampunilah dia, berilah rahmat,kesejahteraan dan ma'afkanlah dia". Apabila jenazah yang disalati itu perempuan, maka bacaan Lahuu diganti dengan Lahaa. Jadi untuk jenazah wanita bacaannyamenjadi: "Allahhummaghfir laha warhamha wa'aafiha wa'fu anha". Jika mayatnya banyak maka bacaan Lahuu diganti dengan Lahum. Jadi untuk jenazah banyak bacaannyamenjadi: "Allahhummaghfir lahum warhamhum wa'aafihim wa'fu anhum"

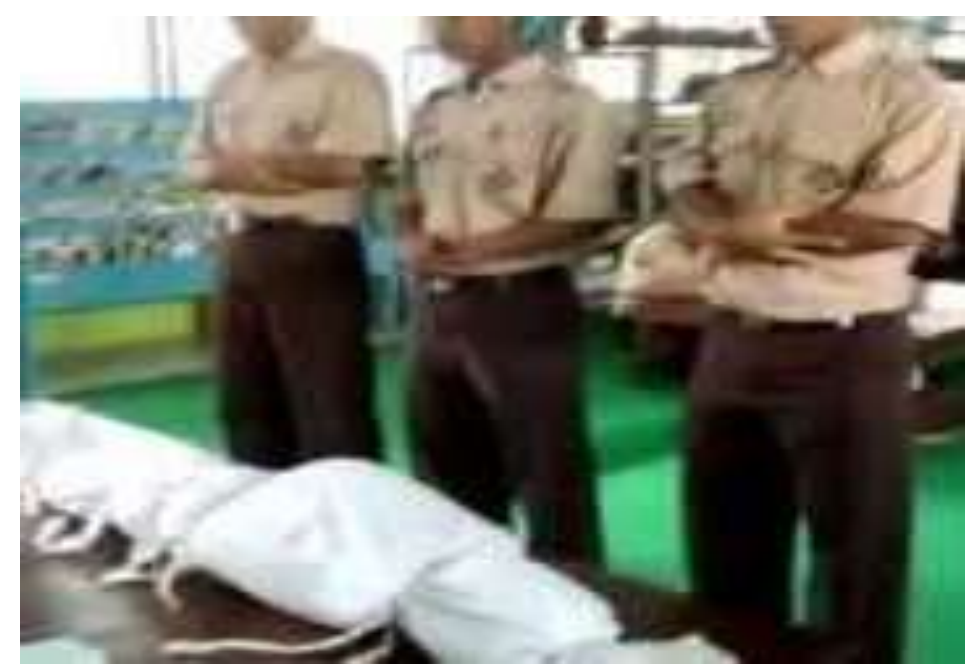

Gambar 5 Mensholatkan Jenazah

\section{Menguburkan Jenazah}

Dalam meletakkan jenazah kedalam liang kubur, hendaknya membaringkan jenazah dengan posisi lambung kanan dibawah dan wajahnya menghadap kea rah kiblat. Sementara kepala dan 
kedua kainya bertumpu pada sisi kanan dan menghadap kiblat. Dimustahabkan (disukai) bagi orang yang mengantar jenazah ke pemakaman untuk melemparkan tiga kali genggaman tanah dengan kedua tangannya usai penutupan liang lahatnya.

Hal-hal yang disunahkan sesudah pemakaman jenazah adalah seperti berikut:

1. Meninggikan kuburan sekadar sejengkal dari permukaan tanah dan tidak diratakan dengan tanah, agar dikenali makamnya dan tidak ditelantarkan.

2. Hendaknya gundukan tanah lebihan dibentuk seperti punuk.

3. Hendaknya member tanda pada makam dengan batu atau sejenisnya agar diketahui bagi keluarganya.

4. Hendaklah salah seorag berdiri di samping kuburan jenazah untuk memohonkan kemantapan dalam menjawab setiap Tanya dalam kubur dan ampunan bagi jenazah, seraya menyuruh kepada yang hadir untuk melakukan hal yang sama.

Kegiatan pengabdian masyarakat pelatihan pengurusan jenazah yang dilakukan pada siswasiswa kelas VIII di MTs Ulumut Qur'an ini telah berlangsung dengan baik. Hal ini terlihat dari kehadiran dan keaktifan siswa ketika kegiatan ini berlangsung. Target peserta pelatihan pengurusan jenazah seperti direncanakan sebelumnya adalah 40 orang siswa di MTs Ulumul Qur'an Medan, sesuai dengan jumlah. Dalam pelaksanaannya, kegiatan ini diikuti oleh 54 orang siswa. Dengan demikian dapat dikatakan bahwa target peserta tercapai $100 \%$ malah melebihi dari target yang direncanakan. Angka tersebut menunjukkan bahwa kegiatan pengabdian pada Masyarakat dilihat dari jumlah peserta yang mengikuti dapat dikatakan berhasil/ sukses yang luar biasa.

Ketercapaian tujuan pelatihan pengurusan jenazah sangat baik, namun keterbatasan waktu yang disediakan mengakibatkan tidak semua materi tentang pengurusan jenazah dapat disampaikan secara detil, yaitu materi tentang menguburkan jenazah. Namun dilihat dari hasil latihan para peserta yaitu pemahaman tentang pengurusan jenazah, maka dapat disimpulkan bahwa tujuan kegiatan ini dapat tercapai. Ketercapaian target materi pada kegiatan Pengabdian pada masyarakat ini cukup baik, karena materi pengurusan jenazah telah dapat disampaikan secara keseluruhan. Dalam evaluasi pada akhir kegiatan ini dicapai pemahaman siswa terhadap pengurusan jenazah semakin baik dan mereka mampu untuk melaksanakan tentang pengurusan jenazah seperti memandikan, mengkafani, mensholatkan jenazah.

\section{Kesimpulan}

Kesimpulan dari kegiatan peningkatan keterampilan pengurusan jenazah adalah:

1. Islam telah mengingatkan kita semua bahwa setiap insan yang bernyawa pasti mengalami kematian. Setiap muslim memiliki kewajiban terhadap saudaranya muslim yang meninggal dunia.

2. Kewajiban ini bersifat kolektif karena itu dimasukkan sebagai suatu jenis ibadah yang hukumnya fardu kifayah, artinya kewajiban bagi seluruh umat muslim, tetapi apabila sudah dilaksanakan oleh beberapa orang yang melaksanakannya, maka gugurlah kewajiban itu bagi seluruh umat muslim.

3. Kewajiban-kewajiban terhadap orang yang meninggal adalah memandikan, mengkafani, menyalatkan, dan menguburkannya. 
4. Siswa-siswa MTs Uumul Qur'an sangat antusias menghadiri kegiatan. Dari jumlah kehadiran siswa saat itu adalah sebanyak 54 orang siswa dari jumlah yang direncanakan sebesar 40 orang siswa mengikuti pelatihan pengurusan jenazah.

\section{Pernyataan}

Penulis mengucapkan terima kasih kepada Dekan Fakultas Syariah dan Hukum Universitas Islam Negeru Sumatera Utara, Dr. Zulham, S.H.I, M. Hum dan Dekan Fakultas Teknik dan Komputer Universitas Harapan Medan, Ir. M. Zulfin, MT yang telah memberikan dukungan moril dan materil sehingga penulis dapat menyelesaikan pengabdian kepada masyarakat beserta diseminasinya tentang pengurusan jenazah ini.

\section{Referensi}

Abdullah Muhammad Bin Yazid al-Quzwaini. 2004. Sunan Ibnu Majah I. Beirut: Dar al-Fikr.

Abdul Karim. (2004). Petunjuk Merawat Jenazah Dan Shalat Jenazah.Jakarta: Amzah

Ad-Dimasyqi, Syaraf An-Nawawi. (2010). Imam Abu Zakariya Yahya Raudhatuththalibin/ Imam abu Zakariya bin Yahya bin Yaraf An-Nawawi AdDimasyqi: Penerjemah, Muhyiddin Mas Rida, Lc, dkk. Jakarta: Pustaka Azzam

A.W Munawwir. (1997). Kamus Al-Munawwir Arab-Indonesia Terlengkap. Surabaya: Pustaka Progressif

Az-Zuhaili, Wahbah. (2011). Fiqih Islam Wa Adillatuhu, Jilid 9. Jakarta: Gema Insani.

Drs. Margiono, M.Pd dkk. (2007). Pendidikan Agama Islam Smk Kelas XI. Ghalia Indonesia, Jakarta

Hassan Shadily. (2000). Kamus Inggris Indonesia An EnglishIndonesia Dictionary. Jakarta : PT. Gramedia.

Kamil Muhammad Uwaidah. (2008). Fiqih Wanita. Jakarta: al-Kauthar.

Rifa'i, Muhammad. (2012). Tuntunan Shalat Lengkap. Semarang: PT.Karya Toha Putra

Riyadi Agus. (2013). Upaya Pemberdayaan Dan Peningkatan Keterampilan Pemulasaraan Jenazah Di Wilayah Kecamatan Mijen Kota Semarang. Jurnal Dimas Vol. 13 No. 2

'Uwaidah, Syaikh Kamil Muhammad. (2003). Fiqh Wanita, diterjemahkan oleh M. Abdul Ghoffar. Jakarta: Pustaka al-Kautsar. 